Article

\title{
Compositional and Morphological Changes in Water-Induced Early-Stage Degradation in Lead Halide Perovskites
}

\author{
Shi Chen ${ }^{1, *}$, Ankur Solanki ${ }^{2,3}$, Jisheng Pan ${ }^{4}\left(\mathbb{D}\right.$ and Tze Chein Sum ${ }^{2} \mathbb{D}$ \\ 1 Institute of Applied Physics and Materials Engineering, University of Macau, Macau, SAR, China \\ 2 Division of Physics and Applied Physics, School of Physical and Mathematical Sciences, Nanyang \\ Technological University, 21 Nanyang Link, Singapore 637371, Singapore \\ 3 Department of Science, School of Technology, Pandit Deendayal Petroleum University, \\ Gandhiagar 382007, India \\ 4 Institute of Materials Research and Engineering, A*STAR (Agency for Science, Technology and Research), 2 \\ Fusionopolis Way, Innovis \#08-03, Singapore 138634, Singapore \\ * Correspondence: shichen@um.edu.mo; Tel.: +852-8822-4294
}

Received: 20 July 2019; Accepted: 14 August 2019; Published: 22 August 2019

check for updates

\begin{abstract}
With tremendous improvements in lead halide perovskite-based optoelectronic devices ranging from photovoltaics to light-emitting diodes, the instability problem stands as the primary challenge in their development. Among all factors, water is considered as one of the major culprits to the degradation of halide perovskite materials. For example, $\mathrm{CH}_{3} \mathrm{NH}_{3} \mathrm{PbI}_{3}\left(\mathrm{MAPbI}_{3}\right)$ and $\mathrm{CH}\left(\mathrm{NH}_{2}\right)_{2} \mathrm{PbI}_{3}\left(\mathrm{FAPbI}_{3}\right)$ decompose into $\mathrm{PbI}_{2}$ in days under ambient conditions. However, the intermediate changes of this degradation process are still not fully understood, especially the changes in early stage. Here we perform an in-situ investigation of the early-stage $\mathrm{MAPbI}_{3}$ and $\mathrm{FAPbI}_{3}$ degradation under high water vapor pressure. By probing the surface and bulk of perovskite samples using near-ambient pressure X-ray photoelectron spectroscopy (NAP-XPS) and XRD, our findings clearly show that $\mathrm{PbI}_{2}$ formation surprisingly initiates below the top surface or at grain boundaries, thus offering no protection as a water-blocking layer on surface or grain boundaries to slow down the degradation process. Meanwhile, significant morphological changes are observed in both samples after water vapor exposure. In comparison, the integrity of $\mathrm{MAPbI}_{3}$ film degrades much faster than the $\mathrm{FAPbI}_{3}$ film against water vapor. Pinholes and large voids are found in $\mathrm{MAPbI}_{3}$ film while only small number of pinholes can be found in $\mathrm{FAPbI}_{3}$ film. However, the $\mathrm{FAPbI}_{3}$ film suffers from its phase instability, showing a fast $\alpha$-to- $\delta$ phase transition. Our results highlight the importance of the compositional and morphological changes in the early stage degradation in perovskite materials.
\end{abstract}

Keywords: halide perovskite; degradation; water; $\mathrm{PbI}_{2}$ formation; morphology

\section{Introduction}

Halide perovskite materials with excellent optoelectronic properties show extensive potential in applications including photovoltaics [1], photodetectors [2], light-emitting diodes, and so on [3]. However, the inherent instability prevents these materials from long-term usage in devices [4]. The two widely used perovskite materials, methylammonium lead triiodide $\left(\mathrm{MAPbI}_{3}\right)$ and formamidinium lead triiodide $\left(\mathrm{FAPbI}_{3}\right)$, are susceptible to degradation by multiple factors, including water, oxygen, UV light, electrical field, and heating [4,5]. Synergistic degradation by the combination of multiple factors were also seen. Recent reports found the degradation process is greatly accelerated when perovskite is exposed to water, oxygen, and light together [6,7]. However, the excess water is still considered as the one of the major culprits causing the degradation of perovskite materials. Without any protection, 
both $\mathrm{MAPbI}_{3}$ and $\mathrm{FAPbI}_{3}$ films cannot last more than a few days in ambient air, quickly decomposed into $\mathrm{PbI}_{2}[8]$.

Based on these observations, two general strategies are proposed to improve device stability. The first strategy is to prevent perovskite layers from making any contact with water. Methods associated with this strategy include encapsulation $[9,10]$ and surface passivation [11]. The second strategy is to enhance the durability of perovskite against water. Methods associated with this strategy include organic and inorganic doping [12-14] and film quality improvement [15]. These efforts successfully extend the lifetime of PSCs to thousands of hours, but still far from fulfilling commercialization requirements [4]. To further extend the lifetime of perovskite materials, new strategy based on thorough understanding of perovskite degradation is needed.

It is clear that $\mathrm{MAPbI}_{3}$ and $\mathrm{FAPbI}_{3}$ decompose into $\mathrm{PbI}_{2}$ at the end, but there are still uncertainties in the process of the degradation. For example, many studies suggest an indirect degradation pathway with sequential formation of two hydrated intermediates, monohydrate $\left(\mathrm{CH}_{3} \mathrm{NH}_{3} \mathrm{PbI}_{3} \cdot \mathrm{H}_{2} \mathrm{O}\right)$ and dihydrate $\left(\left(\mathrm{CH}_{3} \mathrm{NH}_{3}\right)_{4} \mathrm{PbI}_{6} \cdot 2 \mathrm{H}_{2} \mathrm{O}\right)$, during ingress of water [16]. The monohydrate forms first and is reversible, while dihydrate forms only after monohydrate. Prolonged exposure dihydrate with water leads to final decomposition [17]. However, this indirect pathway may not be always valid. Direct $\mathrm{PbI}_{2}$ formation without steps of monohydrate and dihydrate formation was shown in some rigorous studies, raising doubts on the validity of the indirect degradation pathway. Schlipf et al. reported an earlier $\mathrm{PbI}_{2}$ formation than the appearance of monohydrate in their in-situ XRD measurements [18]. Recent near ambient pressure X-ray photoelectron spectroscopy (NAPXPS) study also claimed the surface of a perovskite thin film prepared by thermal deposition quickly decomposed into $\mathrm{PbI}_{2}$ at only $30 \%$ of relative humidity level [19]. Therefore, a direct degradation pathway leading to $\mathrm{PbI}_{2}$ may exist, causing premature deterioration of device performance.

Meanwhile, it is also uncertain the role of $\mathrm{PbI}_{2}$ in degradation. Excessive $\mathrm{PbI}_{2}$ appeared beneficial to the device performance, though it may affect the long-term photostability $[20,21]$. Previous studies usually assumed the $\mathrm{PbI}_{2}$ is formed from the surface, their data usually suggest a linear degradation speed, implying no water-blocking effect from $\mathrm{PbI}_{2}$ layer on surface [22]. Studies using in-vivo XRD measurements confirmed $\mathrm{PbI}_{2}$ formation in sample but was unable to determine whether $\mathrm{PbI}_{2}$ is on the top of surface or not $[8,23]$. $\mathrm{PbI}_{2}$ layer was observed by surface sensitive techniques such as XPS, but in these studies, perovskite films were usually measured after complete decomposition and missed the critical $\mathrm{PbI}_{2}$ formation period [22,24].

Another uncertainty is the effect of morphological change in the early stage of degradation. Morphology is considered as one of the important factors that affects the performance and lifetime of devices. Interestingly, it can be beneficial if a small fraction of water is introduced during fabrication [25]. Improved performance and lifetime are witnessed in these devices. These improvements are believed to be due to increased grain size as well as trap passivation [26,27]. Morphological change may be detrimental if grains are grown too large and cause film disintegration. However, the process at which the film loses its integrity is largely ignored. Previous studies focused on non-morphological changes such as trap passivation and grain boundary variation at early degradation stage $[17,28]$. Others studied much later degradation stage, when the perovskite is completely reverted to $\mathrm{PbI}_{2}[8,29]$. Therefore, the morphology evolution in degradation needs further investigation.

Here we report a study focusing on the critical changes in the early stage of $\mathrm{MAPbI}_{3}$ and $\mathrm{FAPbI}_{3}$ degradation in a precise and controlled condition. Multiple experimental techniques are applied to study water-induced compositional and morphological evolutions under high water vapor pressure at room temperature. Surprisingly, the surface of degraded samples remained stoichiometric to the pristine phase while $\mathrm{PbI}_{2}$ is found in bulk. This finding excludes the possibility of self-passivation by $\mathrm{PbI}_{2}$ and supports the coexistence of both degradation pathways under high water partial pressure condition. Meanwhile, prominent morphological changes such as pinholes and large voids are observed in $\mathrm{MAPbI}_{3}$ sample, revealing loss of film integrity initiated in the early stage degradation. In comparison, $\mathrm{FAPbI}_{3}$ film remains largely intact with much less pinholes, indicating a much slower 
morphology evolution. However, the $\mathrm{FAPbI}_{3}$ sample suffers from water-induced phase change. XRD data show the dominant $\delta$ phase in the degraded $\mathrm{FAPbI}_{3}$ sample, indicating a fast $\alpha$ to $\delta$ phase transition in the early stage of the degradation. Our results successfully clarify compositional and morphological changes in the early-stage degradation of perovskite thin films.

\section{Materials and Methods}

The $\mathrm{MAPbI}_{3}$ sample and $\mathrm{FAPbI}_{3}$ sample are prepared by standard solution preparation methods with anti-solvent treatment. All organic cation salts were purchased from Dyesol (Queanbeyan, Australia) while lead iodide was bought from Acros Organics (Geel, Belgium). $\mathrm{MAPbI}_{3}$ and $\mathrm{FAPbI}_{3}$ perovskite solutions were prepared by mixing precursors in stoichiometric ratio (1 M concentration) in anhydrous dimethylformamide (DMF from Sigma Aldrich, St. Louis, MO, USA). The perovskite thin films were spun-coated on cleaned indium-tin-oxide (ITO) substrates at $5000 \mathrm{rpm}$ for $12 \mathrm{~s}$. The anti-solvent treatment was performed by dripping $100 \mu \mathrm{L}$ toluene on the spinning substrates $9 \mathrm{~s}$ prior to the end of spinning. Subsequently, $\mathrm{MAPbI}_{3}$ samples were annealed at $100{ }^{\circ} \mathrm{C}$ for $30 \mathrm{~min}$ while $\mathrm{FAPbI}_{3}$ samples were annealed at $160^{\circ} \mathrm{C}$ for $10 \mathrm{~min}$. Prepared samples were transferred from glovebox to XPS system through an air-tight container to minimize contact with external atmosphere. XPS measurements were conducted in-situ before and after water vapor dosing in the high-pressure gas cell. SEM and XRD were ex-situ measured before and after water vapor dosing in near-ambient pressure X-ray photoelectron spectroscopy (NAP-XPS) system.

The film crystallinity was measured using Bruker D8 discover X-ray diffractometer (Billerica, MA, USA) with $\mathrm{Cu} \mathrm{K} \alpha$ radiation $(\lambda=1.54 \AA)$. The morphology is measured by JEOL FESEM 6700 (Akishima, Japan). The surface composition was measured by PREVAC NAP-XPS system (Rogow, Poland) with monochromatic $\mathrm{Al} \mathrm{K \alpha} \mathrm{X}$-ray source $(h v=1486.7 \mathrm{eV})$.

\section{Results and Discussion}

To investigate the degradation on the perovskite surface, it is important to control the hydration level precisely. Many previous works used ambient condition with different relative humidity (RH) values to probe the degradation process $[23,30,31]$. However, $\mathrm{RH}$ is not an absolute unit and can largely vary due to temperature change. Therefore, $\mathrm{RH}$ value is not an accurate parameter to measure the content of water. Furthermore, gases in the air such as oxygen may also have implications on the perovskite degradation, making the process more complicated [28,32]. Here we use the gas cell inside a NAPXPS system to study the interaction of perovskite samples to water vapor. The in-situ environment excludes any other external factors and the measured water partial pressure is more accurate than $\mathrm{RH}$ value.

$\mathrm{MAPbI}_{3}$ and $\mathrm{FAPbI}_{3}$ samples are exposed to 23 mbar of water vapor pressure in NAPXPS cells separately for two times with $1 \mathrm{~h}$ each. The water vapor partial pressure is about $80 \% \mathrm{RH}$ for the measured cell temperature of $23{ }^{\circ} \mathrm{C}$. The lower exposure pressure at $18 \mathrm{mbar}$ or below shows no distinguished changes. Extending the exposure time to $6 \mathrm{~h}$ resulted in further decreased XPS intensities as well as $\mathrm{I} / \mathrm{Pb}, \mathrm{N} / \mathrm{Pb}$, and $\mathrm{C} / \mathrm{Pb}$ ratios. Therefore, we only discuss the $2 \mathrm{~h}$ exposure in detail. To monitor potential surface composition changes, XPS high-resolution spectra from $\mathrm{MAPbI}_{3}$ and $\mathrm{FAPbI}_{3}$ before and after water vapor exposure were acquired (Figure 1). It should be highlighted that measurements were done at an ultrahigh vacuum condition after the system was fully recovered from water exposure. Therefore, signals from monohydrate and dihyrate are not expected. For $\mathrm{MAPbI}_{3}$, the spectra of $\mathrm{I} 3 d_{5 / 2}$, $\mathrm{Pb} 4 f$, and $\mathrm{N} 1 s$ contain single peaks at 619.6, 138.8 , and $402.7 \mathrm{eV}$, respectively. All of them originated from $\mathrm{MAPbI}_{3}$ [33]. In the spectrum of $\mathrm{C} 1$ s, two peaks at 286.7 and $285.5 \mathrm{eV}$ can be distinguished. The higher binding energy peak ( $\mathrm{C} 1)$ is from $\mathrm{C}-\mathrm{N}$ bonding in MA cation. The lower binding energy peak (C2) is attributed to the adventitious carbon and it is not related to perovskite itself. The binding energies of carbon peaks are consistent with previous reports [33,34]. After water vapor exposure, peak intensities of $\mathrm{I} 3 d_{5 / 2}, \mathrm{~Pb} 4 f, \mathrm{~N} 1 s$, and $\mathrm{C} 1$ gradually decrease. Only the $\mathrm{C} 2$ peak shows a slight increase. Meanwhile, the peak position remains unchanged. The drop in peak intensities are also 
observed for the $\mathrm{FAPbI}_{3}$ sample (Figure 1e-g). However, the magnitude of the drop is smaller. The relative intensities of different elements are summarized in Figure 2. These intensities in $\mathrm{FAPbI}_{3}$ drop about $10 \%$ to $20 \%$, while in $\mathrm{MAPbI}_{3}$, the intensities drop more than $30 \%$ for iodine and close to $50 \%$ for nitrogen. To clarify if this decrease is related to the decomposition, the normalized atomic ratios between iodine, lead, nitrogen, and $\mathrm{C} 1$ are compared, as listed in Table 1 . For $\mathrm{MAPbI}_{3}$, the $\mathrm{I} / \mathrm{Pb}$ ratio is 3.1 in the pristine sample, indicating a slightly iodine rich on the surface. After the first and second water vapor exposure, this ratio further increased to 3.5 and 3.7, respectively. Meanwhile, the N/Pb ratio and $\mathrm{C} / \mathrm{Pb}$ ratio are also maintained above 1 , indicating no sign of organic cation deficiency at surface. Therefore, the atomic ratio change of $\mathrm{Pb} / \mathrm{I}$ only suggests enrichment of organic cations or deficiency of lead atoms. None of these changes support $\mathrm{PbI}_{2}$ formation. For $\mathrm{FAPbI}_{3}$, the composition change is even smaller. The $\mathrm{I} / \mathrm{Pb}$ ratio is between 3.1-3.6 and N/Pb ratio is between 2.1-2.2. The $\mathrm{C} / \mathrm{Pb}$ ratio is slightly lower than 1 , but no systematic decrease after water vapor exposure was observed. From the atomic ratio data, it can be concluded that there is no sign of $\mathrm{PbI}_{2}$ formation. It appears to contradict a previous NAPXPS study, in which the perovskite surface is completely decomposed at 9 mbar of water partial pressure [19]. This contradiction can be justified by the difference in sample fabrication. Unlike the solution process method, the perovskite films prepared by vacuum deposition usually have smaller domain sizes and poorer crystalline quality. A lower-quality film may result in much faster degradation. Instead, our results are consistent with studies using solution-processed perovskite samples, where no significant surface degradation were reported [24,35].
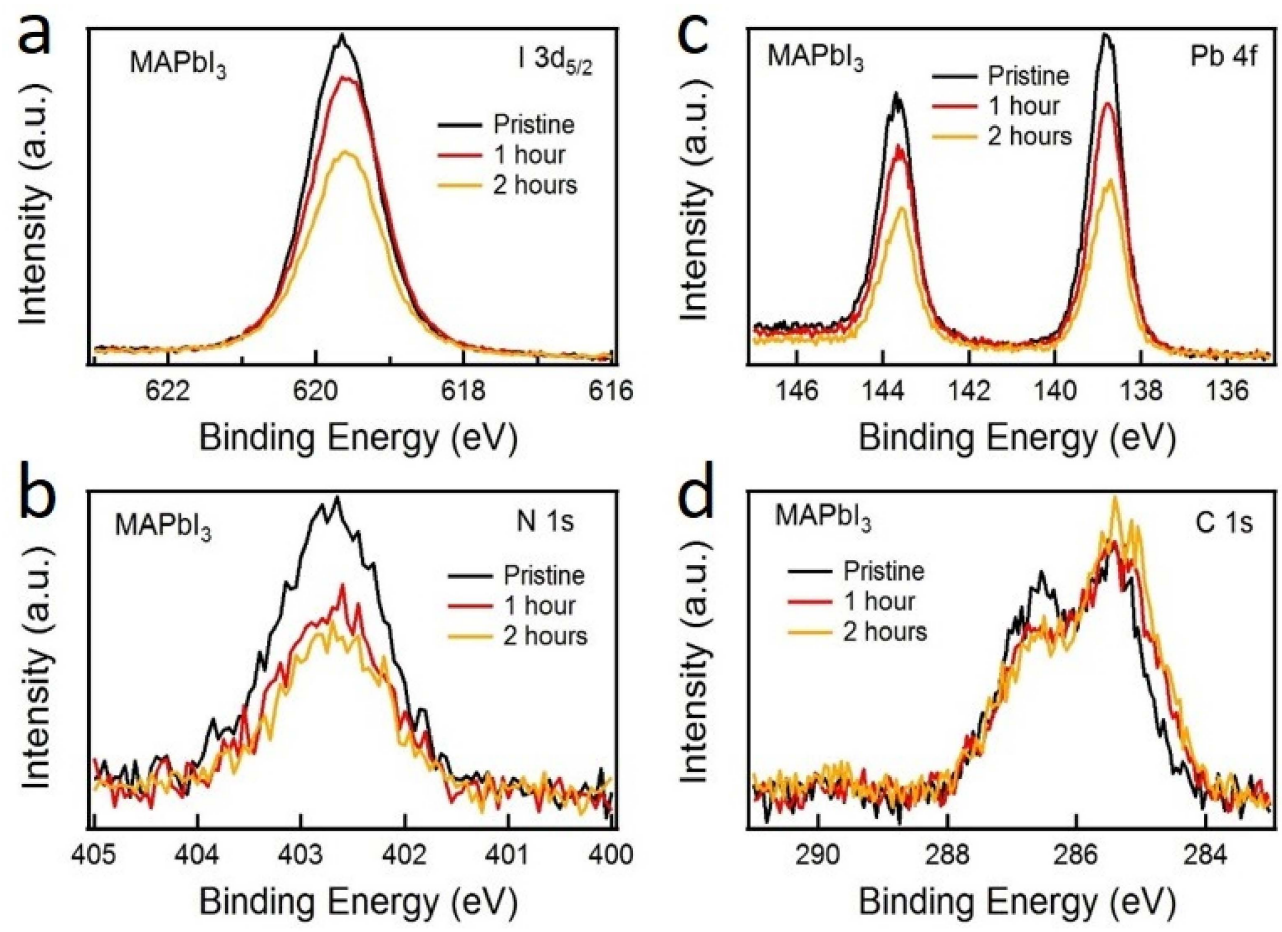

Figure 1. Cont. 

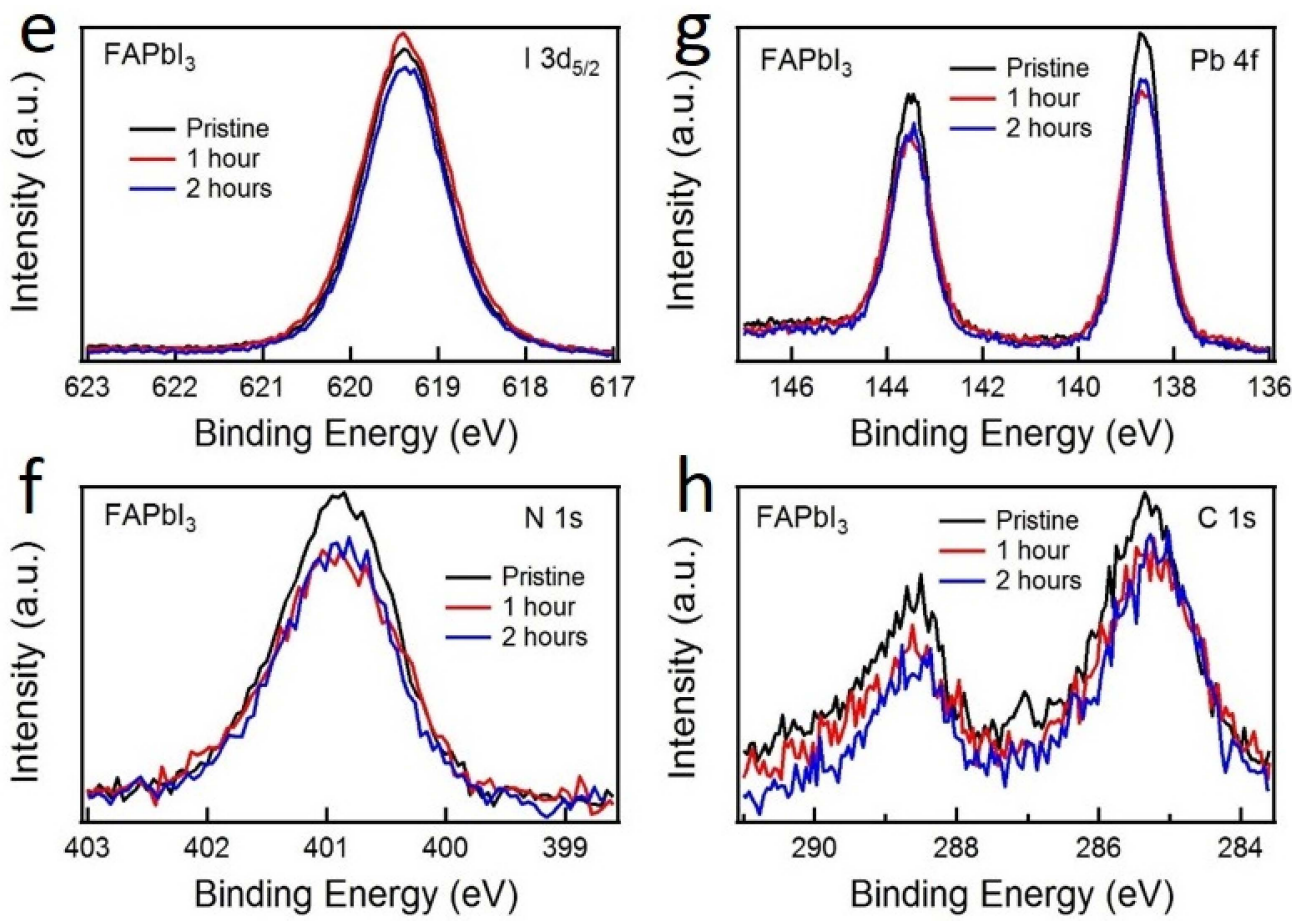

Figure 1. High-resolution spectra of $\mathrm{I} 3 d_{5 / 2}, \mathrm{~N} 1 s, \mathrm{~Pb}$ ff and $\mathrm{C} 1$ s obtained from $\mathrm{MAPbI}_{3}(\mathbf{a}-\mathbf{d})$ and $\mathrm{FAPbI}_{3}(\mathbf{e}-\mathbf{h})$ samples before and after water vapor exposure to different periods, respectively.
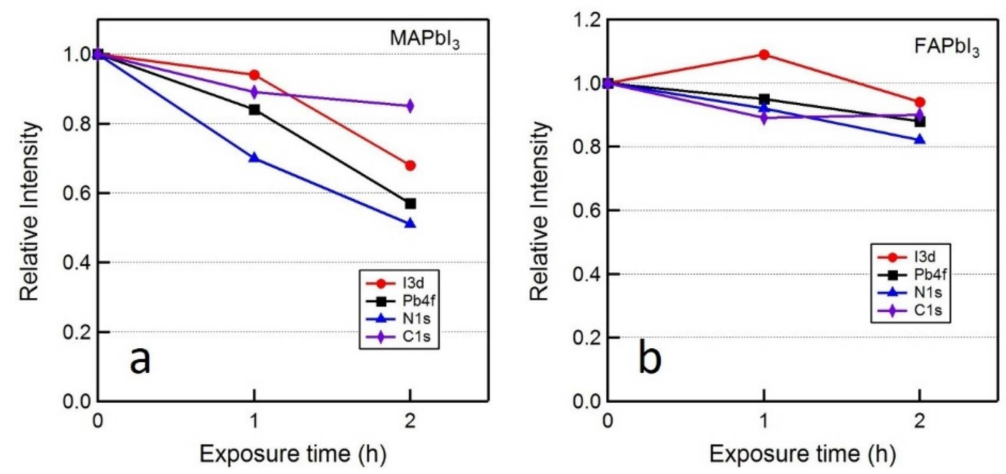

Figure 2. The relative intensities change after different water vapor exposure period. (a) Elemental intensity changes of $\mathrm{MAPbI}_{3}$ sample. (b) Elemental intensity changes of $\mathrm{FAPbI}_{3}$ sample.

Table 1. Atomic ratio of different elements obtained by XPS from $\mathrm{MAPbI}_{3}$ and $\mathrm{FAPbI}_{3}$ before and after water vapor exposure.

\begin{tabular}{ccccccc}
\hline \multirow{2}{*}{ Exposure Time } & \multicolumn{3}{c}{ MAPbI $_{3}$} & \multicolumn{3}{c}{ FAPbI $_{3}$} \\
\cline { 2 - 7 } & $\mathbf{I} / \mathbf{P b}$ & $\mathbf{N} / \mathbf{P b}$ & $\mathbf{C} / \mathbf{P b}$ & $\mathbf{I} / \mathbf{P b}$ & $\mathbf{N} / \mathbf{P b}$ & $\mathbf{C} / \mathbf{P b}$ \\
\hline $0 \mathrm{~h}$ & 3.1 & 1.6 & 1.5 & 3.1 & 2.2 & 0.8 \\
$1 \mathrm{~h}$ & 3.5 & 1.0 & 1.5 & 3.6 & 2.1 & 0.7 \\
$2 \mathrm{~h}$ & 3.7 & 1.5 & 2.4 & 3.3 & 2.1 & 0.9 \\
\hline
\end{tabular}

Since there is no trace of $\mathrm{PbI}_{2}$ formation on the surface, the decrease in intensities is probably due to reduced film coverage. This is supported by the observation in XPS wide scans (Figure 3). After water vapor exposure, new peaks originated from In $3 d$ and O 1s, indicating the partial exposure of ITO substrates. This is clear evidence that large voids form in $\mathrm{MAPbI}_{3}$ thin film. The In $3 d$ signal is much stronger in the $\mathrm{MAPbI}_{3}$ sample, suggesting greater film area shrinkage. Therefore, it can be 
concluded that though the surface composition barely changes, the film coverage greatly reduced. Large voids compromise the device integrity and is probably the determining factor to device lifetime.
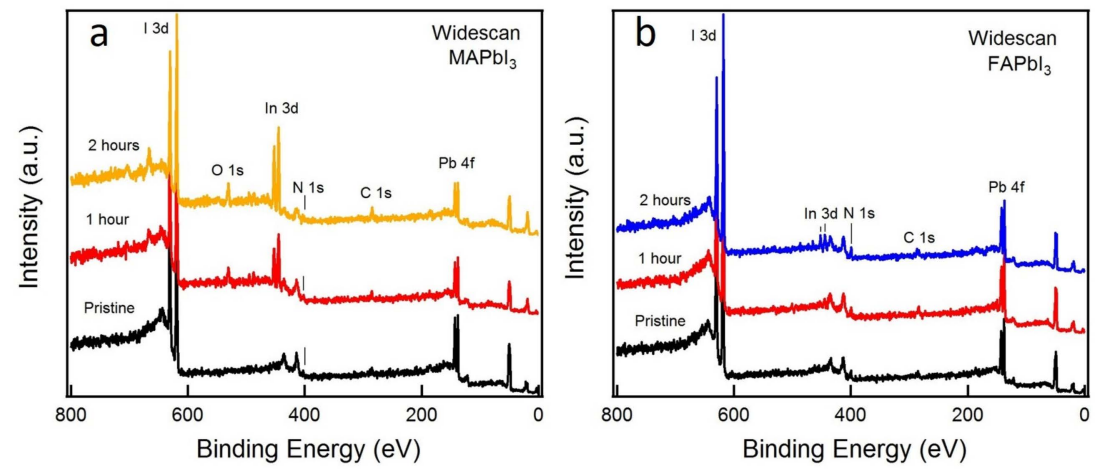

Figure 3. XPS wide scans obtained from $\mathrm{MAPbI}_{3}$ and $\mathrm{FAPbI}_{3}$ samples before and after water vapor exposure. (a) $\mathrm{MAPbI}_{3}$ sample; (b) $\mathrm{FAPbI}_{3}$ sample.

Besides surface sensitive XPS measurements, XRD is used as a complementary technique to evaluate the changes in the bulk. In Figure 4, the XRD spectra of $\mathrm{MAPbI}_{3}$ and $\mathrm{FAPbI}_{3}$ are shown before and after water vapor exposure. The spectra of both pristine samples only contain peaks from

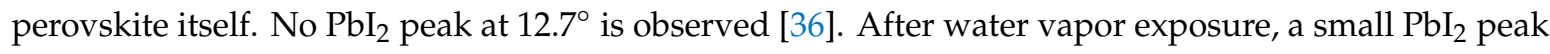
is observed in both samples. Since there is no trace of $\mathrm{PbI}_{2}$ formation on surface, the signal must come from the site below the very top surface. It appears counterintuitive that $\mathrm{PbI}_{2}$ formation starts from the bulk instead of surface. One probable explanation is due to the fast diffusion of water molecules and organic cations $[37,38]$. The water diffusion into the bulk may cause decomposition both inside and on the surface. However, when volatile organic cation escapes via the surface, it may partially compensate the loss of cations at the surface region, delaying $\mathrm{PbI}_{2}$ formation on the surface. It is also possible that part of $\mathrm{PbI}_{2}$ crystals formed along the grain boundaries without much exposure to the top surface. Without surface $\mathrm{PbI}_{2}$ formation, it may be beneficial to keep the interface unchanged, but it also means that slowing down the degradation by $\mathrm{PbI}_{2}$ passivation will not occur. In the $\mathrm{FAPbI}_{3}$ sample, the diffraction peak (001) at $13.8^{\circ}$ disappeared and a peak at $11.8^{\circ}$ emerged. Other high-order peaks also emerged at new two theta degrees. This change is consistent with the $\alpha$-to- $\delta$ phase transition observed in $\mathrm{FAPbI}_{3}$ previously [35]. Therefore, $\mathrm{FAPbI}_{3}$ is more sensitive to water-induced phase change.

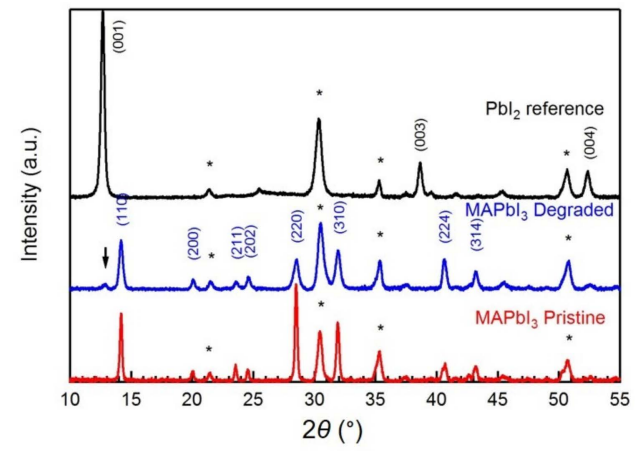

(a)

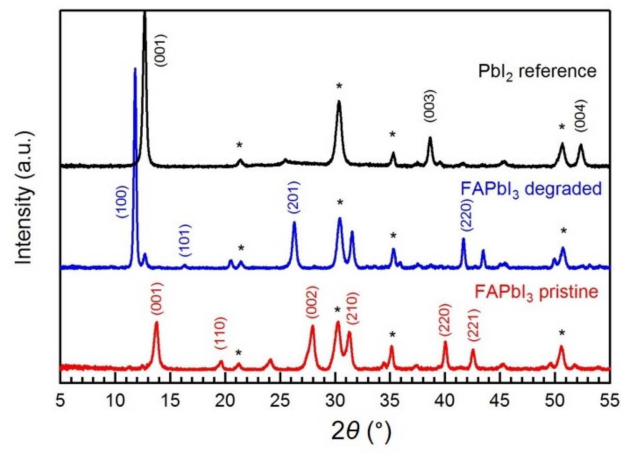

(b)

Figure 4. $\mathrm{XRD}$ data of $\mathrm{MAPbI}_{3}$ and $\mathrm{FAPbI}_{3}$ sample before and after water vapor exposure. $\mathrm{PbI}_{2}$ spectra are shown as a reference. Peaks marked with * is from indium-tin-oxide (ITO) substrate. (a) XRD spectra of the $\mathrm{MAPbI}_{3}$ sample before and after water exposure. (b) XRD spectra of the $\mathrm{FAPbI}_{3}$ sample before and after water exposure.

The XPS data suggest film coverage is reduced after water vapor exposure. To understand how severe the reduction in surface coverage is, the surface of both samples are ex-situ measured by SEM 
(Figure 5). The pristine $\mathrm{MAPbI}_{3}$ film is compact with no observable pinholes, while the $\mathrm{FAPbI}_{3}$ film only contains a few. The $\mathrm{FAPbI}_{3}$ film shows similar grain size with small bright grains on the surface. The formation of these bright grains is probably due to the annealing process to convert the film from $\delta$ phase to $\alpha$ phase. However, during annealing, grain recrystallization also occurs, leaving small grains scattered on the surface. This phenomenon was observed in the previous study as well [39]. After water vapor exposure, the number of pinholes is greatly increased on the $\mathrm{MAPbI}_{3}$ surface. These pinholes are formed along the grain boundaries and do not affect remaining grains. Meanwhile, a grain-coarsening effect is observed. The average grain size has increased from about 0.13 to $0.23 \mu \mathrm{m}^{2}$. All these observations can be attributed to water-induced recrystallization [26]. On the $\mathrm{FAPbI}_{3}$ surface, the increase in pinholes is far less. Instead, needle-like crystals scatter on the surface, probably related to the $\delta$ phase of $\mathrm{FAPbI}_{3}[40]$. In summary, more pinholes are found on the $\mathrm{MAPbI}_{3}$ surface, indicating a poorer morphology stability against water.
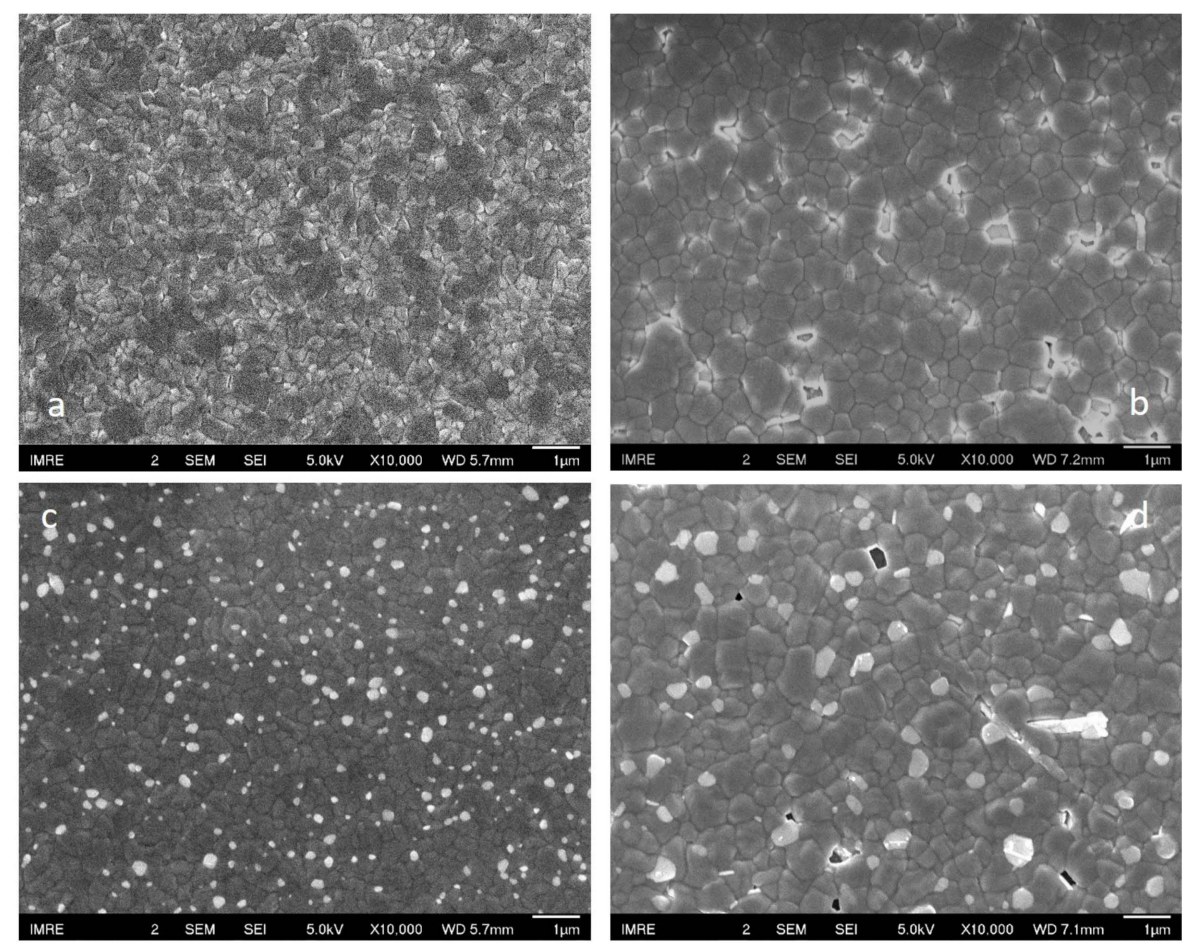

Figure 5. $\mathrm{SEM}$ images of $\mathrm{MAPbI}_{3}$ and $\mathrm{FAPbI}_{3}$ samples before and after water vapor exposure for 2 h. (a) Pristine $\mathrm{MAPbI}_{3}$ sample; (b) $\mathrm{MAPbI}_{3}$ sample after degradation; (c) pristine $\mathrm{FAPbI}_{3}$ sample; (d) $\mathrm{FAPbI}_{3}$ sample after degradation.

Except small pinholes, a much larger-scale reconstruction pattern is also observed on the $\mathrm{MAPbI}_{3}$ surface (Figure 6). This reconstruction is not seen on the $\mathrm{FAPbI}_{3}$ surface. The pattern has a spherulite-like feature with sub-millimeter scale. This pattern was shown in previous works, but its appearance was not discussed $[17,41]$. This spherulite-like pattern is highly symmetric, where each half assembles an alluvial fan. Inside the pattern, the film has been completely reconstructed, forming long crystals with fused boundary pointing towards the joint of two alluvial fans. Meanwhile, voids are seen between reconstructed patterns or between reconstruction pattern and nearby film. The symmetry of this pattern implies the film reconstruction initiates from the center and then spreads out. The formation of these reconstruction center could be due to either localized surface hydrophilic spots, which make water soaking easy or temporary, and localized humidity level variation, which may cause micro water drops formation on the surface, or both. Interestingly, the relative two-fold symmetric alluvial fan-like structure also indicates non-uniform diffusion on the surface. Along preferential water diffusion direction, adsorbed water diffuses much faster, allowing quick bilateral movement of water 
to two opposite ends. At the direction perpendicular to the preferential diffusion direction, water diffuses much slower and does not spread out. It is possible that both monohydrate and dihydrate were formed during recrystallization. However, the film is always measured after water exposure and at ultrahigh vacuum condition. Therefore, from the morphology shown in SEM images, perovskite crystals reversed back from hydrates. The void created by this pattern is much larger than the pinholes formed at grain boundaries. Therefore, it poses a much more severe threat to integrity of devices, and may cause premature device failure. The SEM results are consistent with the XPS data in which nearly $30 \%$ and $10 \%$ of the film area disappeared after water exposure of $\mathrm{MAPbI}_{3}$ and $\mathrm{FAPbI}_{3}$, respectively.

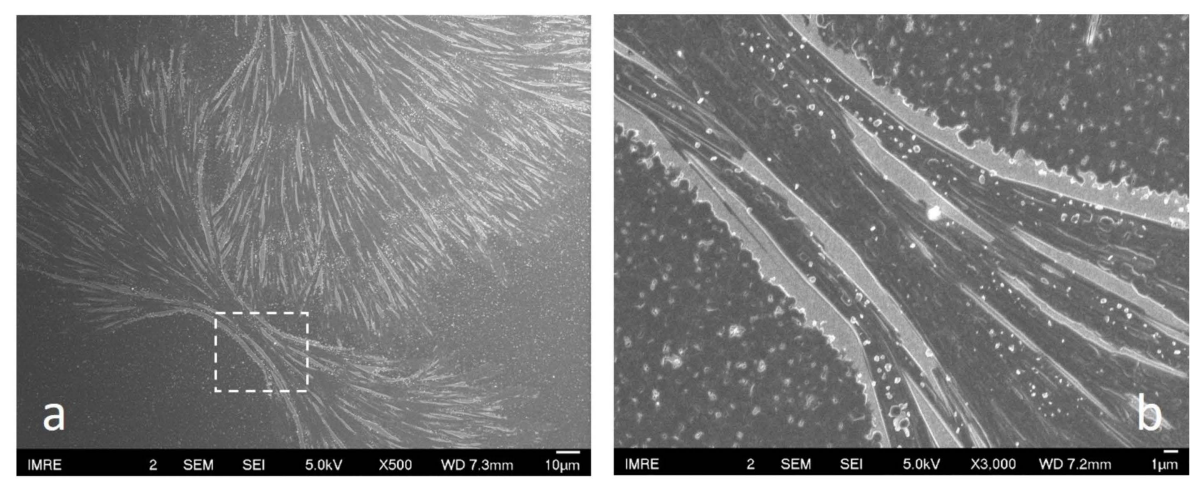

Figure 6. Large-scale morphology changes on the $\mathrm{MAPbI}_{3}$ sample after water exposure. (a) Spherulite-like pattern on the $\mathrm{MAPbI}_{3}$ surface. (b) Zoomed image of the center of spherulite-like pattern.

\section{Conclusions}

In conclusion, we find the degradation of perovskite materials involves multiple changes. For $\mathrm{MAPbI}_{3}$, the initial degradation is dominated by water-induced recrystallization, which causes drastic changes in film morphology. For $\mathrm{FAPbI}_{3}$, the initial change mainly occurs due to the phase transition. For both perovskite films, we reveal the $\mathrm{PbI}_{2}$ formation occurring in the bulk rather than on the surface, probably mainly at grain boundaries. Therefore, $\mathrm{PbI}_{2}$ in the degraded film does not act as a water-blocking barrier to slow down the degradation process. The tendency of $\mathrm{PbI}_{2}$ formation at grain boundaries rather than on the surface is also observed in non-stoichiometric sample with excess $\mathrm{PbI}_{2}$ or stoichiometric samples degraded by heat. Therefore, it can be generally concluded that degradation process of perovskite film is not slowed by the emergence of $\mathrm{PbI}_{2}$. Our results highlight the importance of the external water-blocking layer because $\mathrm{PbI}_{2}$ does not form a continuous film on the surface. Also, a more robust device structure with self-supporting layers may have better resistance to morphology change at the earlier stage of degradation.

Author Contributions: Conceptualization, S.C.; investigation, S.C., A.S., and J.P.; writing-original draft preparation, S.C.; writing-review and editing, S.C., A.S., J.P., and T.C.S., funding acquisition, S.C. and T.C.S.

Funding: This research was funded by Ministry of Education AcRF Tier 2 (MOE2016-T2-1-034), the Singapore National Research Foundation Investigatorship Programme (NRF-NRFI-2018-04) and the University of Macau startup fund (SRG2018-00140-IAPME).

Acknowledgments: Authors acknowledge technical support in experiments from Lim Poh Chong and Bussolotti Fabio in IMRE.

Conflicts of Interest: The authors declare no conflict of interest.

\section{References}

1. Yang, W.S.; Park, B.-W.; Jung, E.H.; Jeon, N.J.; Kim, Y.C.; Lee, D.U.; Shin, S.S.; Seo, J.; Kim, E.K.; Noh, J.H.; et al. Iodide management in formamidinium-lead-halide-based perovskite layers for efficient solar cells. Science 2017, 356, 1376-1379. [CrossRef] [PubMed]

2. Dou, L.T.; Yang, Y.; You, J.B.; Hong, Z.R.; Chang, W.H.; Li, G.; Yang, Y. Solution-processed hybrid perovskite photodetectors with high detectivity. Nat. Commun. 2014, 5, 5404. [CrossRef] [PubMed] 
3. Du, B.; Xia, Y.; Wei, Q.; Xing, G.; Chen, Y.; Huang, W. All-inorganic perovskite nanocrystals-based light emitting diodes and solar cells. Chemnanomat 2019, 5, 266-277. [CrossRef]

4. Leijtens, T.; Eperon, G.E.; Noel, N.K.; Habisreutinger, S.N.; Petrozza, A.; Snaith, H.J. Stability of metal halide perovskite solar cells. Adv. Energy Mater. 2015, 5, 1500963. [CrossRef]

5. Li, B.; Li, Y.; Zheng, C.; Gao, D.; Huang, W. Advancements in the stability of perovskite solar cells: Degradation mechanisms and improvement approaches. RSC Adv. 2016, 6, 38079-38091. [CrossRef]

6. Aristidou, N.; Eames, C.; Islam, M.S.; Haque, S.A. Insights into the increased degradation rate of $\mathrm{CH}_{3} \mathrm{NH}_{3} \mathrm{PbI}_{3}$ solar cells in combined water and $\mathrm{O}_{2}$ environment. J. Mater. Chem. A 2017, 5, 25469-25475. [CrossRef]

7. Norbert, H.N.; Felix, L.; Brus, V.V.; Shargaieva, O.; Rappich, J. Unraveling the light-induced degradation mechanisms of $\mathrm{CH}_{3} \mathrm{NH}_{3} \mathrm{PbI}_{3}$ perovskite film. Adv. Electron. Mater. 2017, 3, 1700158. [CrossRef]

8. Habisreutinger, S.N.; Leijtens, T.; Eperon, G.E.; Stranks, S.D.; Nicholas, R.J.; Snaith, H.J. Carbon nanotube/polymer composites as a highly stable hole collection layer in perovskite solar cells. Nano Lett. 2014, 14, 5561-5568. [CrossRef]

9. Wei, Z.; Zheng, X.; Chen, H.; Long, X.; Wang, Z.; Yang, S. A multifunctional C + epoxy/Ag-paint cathode enables efficient and stable operation of perovskite solar cells in watery environments. J. Mater. Chem. A 2015, 3, 16430-16434. [CrossRef]

10. Bella, F.; Griffini, G.; Correa-Baena, J.-P.; Saracco, G.; Gratzel, M.; Hagfeldt, A.; Turri, S.; Gerbaldi, C. Improving efficiency and stability of perovskite solar cells with photocurable fluoropolymers. Science 2016, 354, 203-206. [CrossRef]

11. Yang, S.; Wang, Y.; Liu, P.; Cheng, Y.; Zhao, H.; Yang, H. Functionalization of perovskite thin films with moisture-tolerant molecules. Nat. Energy 2016, 1, 15016. [CrossRef]

12. Hu, Y.; Qiu, T.; Bai, F.; Miao, X.; Zhang, S. Enhancing moisture-tolerance and photovoltaic performances of FAPbI3 by bismuth incorporation. J. Mater. Chem. A 2017, 5, 25258-25265. [CrossRef]

13. Wang, Z.; Lin, Q.; Chmiel, F.P.; Sakai, N.; Herz, L.M.; Snaith, H.J. Efficient ambient-air-stable solar cells with 2D-3D heterostructured butylammonium-caesium-formamidinium lead halide perovskites. Nat. Energy 2017, 2, 17135. [CrossRef]

14. Saidaminov, M.I.; Kim, J.; Jain, A.; Quintero-Bermudez, R.; Tan, H.; Long, G.; Tan, F.; Johnston, A.; Zhao, Y.; Voznyy, O.; et al. Suppression of atomic vacancies via incorporation of isovalent small ions to increase the stability of halide perovskite solar cells in ambient air. Nat. Energy 2018, 3, 648-654. [CrossRef]

15. Kim, J.H.; Williams, S.T.; Cho, N.; Chueh, C.-C.; Jen, A.K.-Y. Enhanced environmental stability of planar heterojunction perovskite solar cells based on blade-coating. Adv. Energy Mater. 2015, 5, 1401229. [CrossRef]

16. Song, Z.; Abate, A.; Watthage, S.C.; Liyanage, G.K.; Phillips, A.B.; Steiner, U.; Graetzel, M.; Heben, M.J. Perovskite solar cell stability in humid air: Partially reversible phase transitions in the $\mathrm{PbI}_{2}-\mathrm{CH}_{3} \mathrm{NH}_{3} \mathrm{I}-\mathrm{H}_{2} \mathrm{O}$ system. Adv. Energy Mater. 2016, 6, 1600846. [CrossRef]

17. Leguy, A.M.A.; Hu, Y.; Campoy-Quiles, M.; Alonso, M.I.; Weber, O.J.; Azarhoosh, P.; van Schilfgaarde, M.; Weller, M.T.; Bein, T.; Nelson, J.; et al. Reversible hydration of $\mathrm{CH}_{3} \mathrm{NH}_{3} \mathrm{PbI}_{3}$ in films, single crystals, and solar cells. Chem. Mater. 2015, 27, 3397-3407. [CrossRef]

18. Schlipf, J.; Hu, Y.H.; Pratap, S.; Bießmann, L.; Hohn, N.; Porcar, L.; Bein, T.; Docampo, P.; Muller-Buschbaum, P. Shedding light on the moisture stability of 3D/2D hybrid perovskite heterojunction thin films. ACS Appl. Energy Mater. 2019, 2, 1011-1018. [CrossRef]

19. Ke, J.C.-R.; Walton, A.S.; Lewis, D.J.; Tedstone, A.; O’Brien, P.; Thomas, A.G.; Flavell, W.R. In situ investigation of degradation at organometal halide perovskite surfaces by X-ray photoelectron spectroscopy at realistic water vapour pressure. Chem. Commun. 2017, 53, 5231-5234. [CrossRef]

20. Bi, D.; Tress, W.; Dar, M.I.; Gao, P.; Luo, J.; Renevier, C.; Schenk, K.; Abate, A.; Giordano, F.; Baena, J.-P.C.; et al. Efficient luminescent solar cells based on tailored mixed-cation perovskites. Sci. Adv. 2016, 2, e1501170. [CrossRef]

21. Jesper, J.; Juan-Pablo, C.B.; Elham, H.A.; Bertrand, P.; Samuel, D.S.; Marine, E.F.B.; Wolfgang, T.; Kurt, S.; Joel, T.; Jacques, E.M.; et al. Unreacted $\mathrm{PbI}_{2}$ as a double-edge sword for enhancing the performance of perovskite solar cells. J. Am. Chem. Soc. 2016, 138, 10331-10343. [CrossRef]

22. Wang, C.C.; Gao, Y.L. Stability of perovskites at the surface analytic level. J. Phys. Chem. Lett. 2018, 9, 4657-4666. [CrossRef] [PubMed]

23. Wei, W.; $\mathrm{Hu}$, Y.H. Catalytic role of $\mathrm{H}_{2} \mathrm{O}$ in degradation of inorganic-organic perovskite $\left(\mathrm{CH}_{3} \mathrm{NH}_{3} \mathrm{PbI}_{3}\right)$ in air. Int. J. Energy Res. 2017, 41, 1063-1069. [CrossRef] 
24. Philippe, B.; Park, B.-W.; Lindblad, R.; Oscarsson, J.; Ahmadi, S.; Johansson, E.M.J.; Rensmo, H. Chemical and electronic structure characterization of lead halide perovskites and stability behavior under different exposures-A photoelectron spectroscopy investigation. Chem. Mater. 2015, 27, 1720-1731. [CrossRef]

25. You, J.; Yang, Y.; Hong, Z.; Song, T.B.; Meng, L.; Liu, Y.; Jiang, C.; Zhou, H.; Chang, W.H.; Li, G.; et al. Moisture assisted perovskite film growth for high performance solar cells. Appl. Phys. Lett. 2014, 105, 183902. [CrossRef]

26. Zhang, W.; Xiong, J.; Li, J.; Daoud, W.A. Mechanism of water effect on enhancing the photovoltaic performance of triple-cation hybrid perovskite solar cells. ACS Appl. Mater. Interfaces 2019, 11, 12699-12708. [CrossRef]

27. Solanki, A.; Lim, S.S.; Mhaisalkar, S.; Sum, T.C. Role of water in suppressing recombination pathways in $\mathrm{CH}_{3} \mathrm{NH}_{3} \mathrm{PbI}_{3}$ perovskite solar cells. ACS Appl. Mater. Interfaces 2019, 11, 25474-25482. [CrossRef]

28. Yang, J.M.; Yuan, Z.C.; Liu, X.J.; Braun, S.; Li, Y.Q.; Tang, J.X.; Gao, F.; Duan, C.G.; Fahlman, M.; Bao, Q.Y. Oxygen- and water-induced energetics degradation in organometal halide perovskites. ACS Appl. Mater. Interfaces 2018, 10, 16225-16230. [CrossRef]

29. Christians, J.A.; Miranda Herrera, P.A.; Kamat, P.V. Transformation of the excited state and photovoltaic efficiency of $\mathrm{CH}_{3} \mathrm{NH}_{3} \mathrm{PbI}_{3}$ perovskite upon controlled exposure to humidified Air. J. Am. Chem. Soc. 2015, 137, 1530-1538. [CrossRef]

30. Shirayama, M.; Kato, M.; Miyadera, T.; Sugita, T.; Fujiseki, T.; Hara, S.; Kadowaki, H.; Murata, D.; Chikamatsu, M.; Fujiwara, H.; et al. Degradation mechanism of $\mathrm{CH}_{3} \mathrm{NH}_{3} \mathrm{PbI}_{3}$ perovskite materials upon exposure to humid air. J. Appl. Phys. 2016, 119, 115501. [CrossRef]

31. Li, D.; Bretschneider, S.A.; Bergmann, V.W.; Hermes, I.M.; Mars, J.; Klasen, A.; Lu, H.; Tremel, W.; Mezger, M.; Butt, H.J.; et al. Humidity-induced grain boundaries in $\mathrm{MAPbI}_{3}$ perovskite films. J. Phys. Chem. C 2016, 120, 6363-6368. [CrossRef]

32. Ralaiarisoa, M.; Salzmann, I.; Zu, F.S.; Koch, N. Effect of water, oxygen, and air exposure on $\mathrm{CH}_{3} \mathrm{NH}_{3} \mathrm{PbI}_{3-x} \mathrm{Cl}_{x}$ perovskite surface electronic properties. Adv. Electron. Mater. 2018, 4, 1800307. [CrossRef]

33. Chen, S.; Goh, T.W.; Sabba, D.; Chua, J.; Mathews, N.; Huan, C.H.A.; Sum, T.C. Energy level alignment at the methylammonium lead iodide/copper phthalocyanine interface. APL Mater. 2014, 2, 081512. [CrossRef]

34. Hawash, Z.; Raga, S.R.; Son, D.Y.; Ono, L.K.; Park, N.G.; Qi, Y.B. Interfacial modification of perovskite solar cells using an ultrathin MAI layer leads to enhanced energy level alignment, efficiencies, and reproducibility. J. Phys. Chem. Lett. 2017, 8, 3947-3953. [CrossRef] [PubMed]

35. Yamanaka, S.; Hayakawa, K.; Cojocaru, L.; Tsuruta, R.; Sato, T.; Mase, K.; Uchida, S.; Nakayama, Y. Electronic structures and chemical states of methylammonium lead triiodide thin films and the impact of annealing and moisture exposure. J. Appl. Phys. 2018, 123, 165501. [CrossRef]

36. Smecca, E.; Numata, Y.; Deretzis, I.; Pellegrino, G.; Boninelli, S.; Miyasaka, T.; La Magna, A.; Alberti, A. Stability of solution-processed $\mathrm{MAPbI}_{3}$ and $\mathrm{FAPbI}_{3}$ layers. Phys. Chem. Chem. Phys. 2016, 18, 13413-13422. [CrossRef] [PubMed]

37. Sun, P.P.; Chi, W.J.; Li, Z.S. Effects of water molecules on the chemical stability of $\mathrm{MAGeI}_{3}$ perovskite explored from a theoretical viewpoint. Phys. Chem. Chem. Phys. 2016, 18, 24526-24536. [CrossRef] [PubMed]

38. Tong, C.; Geng, W.; Tang, Z.; Yam, C.; Fan, X.; Liu, J.; Lau, W.; Liu, L. Uncovering the veil of the degradation in perovskite $\mathrm{CH}_{3} \mathrm{NH}_{3} \mathrm{PbI}_{3}$ upon humidity exposure: A first-principles study. J. Phys. Chem. Lett. 2015, 6, 3289-3295. [CrossRef]

39. Liu, T.; Zong, Y.; Zhou, Y.; Yang, M.; Li, Z.; Game, O.S.; Zhu, K.; Zhu, R.; Gong, Q.; Padture, N.P. High-performance formamidinium-based perovskite solar cells via microstructure-mediated $\delta$-to- $\alpha$ phase transformation. Chem. Mater. 2017, 29, 3246-3250. [CrossRef]

40. Tseng, W.S.; Jao, M.H.; Hsu, C.C.; Huang, J.S.; Wu, C.I.; Yeh, N.C. Stabilization of hybrid perovskite $\mathrm{CH}_{3} \mathrm{NH}_{3} \mathrm{PbI}_{3}$ thin films by graphene passivation. Nanoscale 2017, 9, 19227-19235. [CrossRef]

41. Yang, J.L.; Fransishyn, K.M.; Kelly, T.L. Comparing the effect of mesoporous and planar metal oxides on the stability of methylammonium lead iodide thin films. Chem. Mater. 2016, 28, 7344-7352. [CrossRef]

(C) 2019 by the authors. Licensee MDPI, Basel, Switzerland. This article is an open access article distributed under the terms and conditions of the Creative Commons Attribution (CC BY) license (http://creativecommons.org/licenses/by/4.0/). 